Wilfrid Laurier University

Scholars Commons @ Laurier

Psychology Faculty Publications

Psychology

2017

\title{
Why Be Moral? Moral Identity Motivation and Age
}

Tobias Krettenauer

Wilfrid Laurier University, tkrettenauer@wlu.ca

Rosemary Victor

Follow this and additional works at: https://scholars.wlu.ca/psyc_faculty

Part of the Psychiatry and Psychology Commons

\section{Recommended Citation}

Krettenauer, Tobias and Victor, Rosemary, "Why Be Moral? Moral Identity Motivation and Age" (2017). Psychology Faculty Publications. 110.

https://scholars.wlu.ca/psyc_faculty/110

This Article is brought to you for free and open access by the Psychology at Scholars Commons @ Laurier. It has been accepted for inclusion in Psychology Faculty Publications by an authorized administrator of Scholars Commons@Laurier. For more information, please contact scholarscommons@wlu.ca. 
Running head: MORAL IDENTITY MOTIVATION

Why Be Moral? Moral Identity Motivation and Age

Tobias Krettenauer \& Rosemary Victor

Krettenauer, T. \& Victor, R. (2017). Why be moral? Moral identity motivation and age. Developmental Psychology, 53, 1589-1596, http://dx.doi.org/10.1037/dev0000353

Author Note

Tobias Krettenauer, Rosemary Victor, Department of Psychology, Wilfrid Laurier University, Waterloo, Canada.

The research presented in this paper was supported by an Insight Grant of the Social Sciences and Humanities Research Council Canada to the first author (\#435-2012-1070).

Please address correspondence concerning this article to: Tobias Krettenauer, Department of Psychology, Wilfrid Laurier University, 75 University Ave W, Waterloo, Ontario, N2L 3C5, Canada; email: tkrettenauer@wlu.ca. 


\begin{abstract}
Moral identity research up to date has largely failed to provide evidence for developmental trends in moral identity presumably because of restrictions in the age range of studies and the use of moral identity measures that are insensitive to age-related change. The present study investigated moral identity motivation across a broad age range (14-65 years, $N=252, M=$ 33.48 years) using a modified version of the Good-Self Assessment Interview (Arnold, 1993). Individuals' moral identity motivation was coded and categorized as external, internal or relationship-oriented. It was found that with age external moral identity motivation decreased, whereas internal moral identity motivation increased. Effects of age were stronger in adolescence and emerging adulthood than in young adulthood and middle age. Findings underscore the developmental nature of the moral identity construct and suggest that moral motivation becomes more self-integrated with age.
\end{abstract}

Key words: moral identity, moral motivation, moral development 
Moral identity, defined as "the degree to which being a moral person is important to an individual's identity" (Hardy \& Carlo, 2011, p. 212), has been discussed repeatedly as a developmental construct. Yet, empirical evidence in support of moral identity development is scarce. Few studies systematically investigated age-related trends in moral identity in the past but failed to document any (for details see Krettenauer \& Hertz, 2015). Krettenauer and Hertz (2015) argued that the lack of empirical evidence for moral identity development may be due to (a) limited age range of studies as well as (b) issues of conceptualization and measurement. Consistent with this view, Krettenauer, Murua, and Jia (2016) found that increasing the agerange under study reveals continuous age-related increases in the self-importance of moral values from adolescence throughout adulthood (14 to 65 years).

Self-importance of moral values represents one aspect of moral identity. However, as Krettenauer (2011) pointed out, self-importance of moral values needs to be distinguished from moral identity motivation. Individuals may agree that morality is important to them, yet express different motives for its personal importance. Note that moral identity motivation is not equivalent to motivation for moral action. As Frankena (1963) pointed out, moral motivation is complex. It consists of motives for action (e.g., the intention to help someone in need) as well as the motivation to prioritize moral concerns over personal or conventional issues (e.g., to help someone in need even at considerable personal costs). The assumption that moral identity provides a motive for moral action is problematic as it suggests ethical egoism (moral motivation would be equivalent with the intention to do what is important to the self, cf. Nucci, 2004). This is not implied in the notion of moral identity motivation defined as an individual's motivation to uphold moral intentions in the face of other, potentially conflicting concerns. Moral identity 
motivation is not limited to overt moral action but includes many aspects of decision-making and judgment formation.

According to Self-Determination Theory (SDT, Deci \& Ryan, 2012), the motivation to meet social expectations or to comply with cultural norms can be external or internal to the self (see also Assor, 2012). External motivation (also defined as controlled motivation) is either based on self-interest or is introjected (Ryan \& Connell, 1989). Introjected motivation involves avoidance of negative self-evaluation and seeking positive approval by others. Internal (autonomous) motivation, by contrast, is described as identified or integrated. Identified motivation is based on evaluative standards that are considered as important to the self. Integrated motivation involves self-ideals and reflects the type of person one wants to be. Applied to helping behaviour, for instance, external (controlled) motivation is expressed in the motif to avoid appearing as a bad person and the desire to be liked by others (Weinstein \& Ryan 2010). By contrast, internal (autonomous) motivation is expressed in the desire of caring for others and in positively valuing the act of helping in itself. It is important to note that autonomy from the perspective of SDT is not a stage-like attribute that once achieved is maintained across a broad range of domains. Rather it is considered a context-specific person characteristic that depends on supportive environmental factors to develop (Deci \& Ryan, 2014).

Age-related increases in internal motivation over the life span have been documented for personal goals (Sheldon \& Kasser, 2001) and for social role obligations (Sheldon, Kasser, Houser-Marko, Jones, \& Turban, 2005) but not for moral identity. Correspondingly, Krettenauer and Hertz (2015) identified growth of internal motivation as one important aspect of moral identity development that has been largely neglected in the past. In the present study, we 
investigated relationships between age and moral identity motivation in an effort to further substantiate the notion of moral identity development.

How do external (controlled) and internal (autonomous) forms of moral identity motivation relate to age in adolescence and adulthood? Do age-related differences in moral identity motivation depend on context? These were the leading questions for the present study. In line with previous research (Sheldon et al., 2005), internal moral identity motivation was expected to be positively correlated with age, whereas a negative correlation was expected for external moral identity motivation and age. These expectations are consistent with SDT, which proposes a general developmental trend towards internal modes of motivation (Deci \& Ryan, 2014). When applied to moral development, however, it is yet to be determined whether this tendency receives equal support across different domains. It might be that the moral demand characteristics in some areas of life (e.g., family) are more supportive of developing an internal (autonomous) moral identity motivation, unlike other contexts (such as the workplace). As a consequence, internal moral identity motivation may be context-specific. Context specificity in the development of internal motivation has been previously documented for the age period of adolescence (Renaud-Dubé, Taylor, Lekes, Koestner, \& Guay, 2010).

In addition to examining age-related differences in moral identity motivation across various social contexts, it was investigated how these differences relate to the second aspect of moral identity described above: self-importance of moral values. As demonstrated by Krettenauer et al. (2016), self-importance of moral values tends to increase from adolescence through adulthood. Age-related differences in moral identity motivation may reflect changes in self-importance of moral values, at least partially. 


\section{Methods}

\section{Sample}

The sample consisted of 252 individuals (148 women) of four different age groups of approximately equal size: adolescence (14-18 years), emerging adulthood (19-25 years), young adulthood (26-45 years) and middle age (46-65 years). Age-group was unrelated to gender, $\chi^{2}=$ $2.54, d f=3, p=.45$. Table 1 provides a breakdown of all demographic variables by age group.

Participants were recruited through advertisements in local newspapers, online postings of the study and flyers distributed at community events. All participants provided informed consent before participating and received $\$ 50$ compensation.

At time of data collection, all participants were residing in South-West Ontario. Most participants (76.1\%) self-identified themselves as Canadian of European descent. Of participants, $14.9 \%$ had an Asian or East-Asian background and described themselves as Indian, Pakistani, Chinese or Vietnamese, and 9\% self-identified as Arabian or Arabic. In the present sample, ethnic background (European-Canadian, $1=$ yes vs. $0=n o$ ) was neither related to age-group, $\chi^{2}$ $=5.93, d f=3, p=.11$, nor to gender, $\chi^{2}=1.45, d f=1, p=.23$ (for details see Table 1$)$.

Of participants, $40.8 \%$ were enrolled in a secondary or post-secondary educational institution (high-school, college or university). Of those participants who were not enrolled in an educational institution $(n=150)$, the majority had obtained a college diploma or undergraduate degree (see Table 1). Educational attainment was unrelated to age-group, $\chi^{2}=1.04, d f=4, p=$ 91 .

For assessing socio-economic status (SES), the International Socio-Economic Index of Occupational Status (ISEI) was used (Ganzeboom, De Graaf, \& Treiman, 1992). In the present 
sample, participants' ISEI score was average (see Table 1). The four age-groups did not differ with regard to SES, $F(3,219)=0.29, p=0.83$.

\section{Moral Identity Interview}

The study consisted of a 90-minute interview and a questionnaire that took about 30 minutes to complete. In the present paper, only interview data were used.

The interview procedure for assessing individuals' moral identity was based on a modified version of the Good Self-Assessment (Arnold, 1993) which has been validated in several independent studies (Barriga, Morrison, Liau, \& Gibbs, 2001; Johnston \& Krettenauer, 2011; Nunner-Winkler, Meyer-Nikele, \& Wohlrab, 2007). Modifications pertained to (a) the value-attributes individuals use to define their moral identity, and (b) the context-specific assessment of moral identity. Whereas the Good-Self-Assessment uses a standard list of eight moral values to assess a person's moral identity (e.g., fair, truthful, kind), in the present study, participants were asked to define their moral identity by choosing from a longer list of 80 valueattributes. These value-attributes were used to assess the self-importance of morality separately in three different social contexts: family, work or school (depending on participants' employment status), and community/society.

The list of 80 value-attributes that was used for asking participants to define their moral identity was derived from studies that previously had investigated individuals' prototypical conceptions of a moral person (for a full list of all 80 attributes, see Appendix). The valueattributes people use to characterize a highly moral person typically belong to the domains of benevolence, universalism, conformity, achievement and self-direction in Schwartz' circumplex model of human values (Vauclair, Wilson, \& Fischer, 2014). This finding corresponds with Moral Foundations Theory, which points out that the moral domain goes beyond the two moral 
foundations of harm and fairness (which correspond to benevolence and universalism) (Graham et al., 2011). While benevolence and universalism constitute core moral values, people sometimes include value-attributes in their conception of a highly moral person that have been characterized as social-conventional from the perspective of domain theory (cf. Smetana, Jambon \& Ball, 2014). In the present study, we did not adopt a specific conceptual definition of the moral domain but let individuals chose the values that define their moral identity.

To familiarize participants with all attributes, they were first asked to rate all 80 characteristics according to how well they describe a highly moral person on a 5-point scale. Participants were then asked to select those 12 to 15 attributes that according to their own personal view, define "the core of a highly moral person". In the sample, the average number of chosen value-attributes was $14.15, S D=1.09$. Participant age was unrelated to the number of attributes chosen, $r(250)=.09, p=0.27$.

To assess the self-importance of the chosen attributes, participants were given a set of magnetic labels with the chosen attributes and a diagram that displayed three nested circles representing varying levels of self-importance (from not important to me at the outer periphery to very important to me at the center of the diagram). There were three diagrams with different headings, representing the social contexts of family, work or school, and community/society. Participants worked on the three diagrams consecutively in randomized order.

After completion of each diagram, motives for the importance of those moral values that were placed in the center of the diagram designated as "very important to me" were probed in depth. Interviewers introduced the topic by the standard question "You put at the center of the diagram. Why are these qualities very important to you in the context of __?". This question was followed by prompts to further elaborate on the initial response. 
Interviewees were asked to give explanations for the personal importance of each valueattribute. However, in order to reduce redundancy in the interview procedure and avoid boredom, participants were allowed to combine similar value-attributes and explain the personal importance of groups of attributes. Thus, participants were not forced to elaborate on the importance of each value-attribute separately if they chose not to do so.

On average, 6-7 attributes were placed in the center of each diagram. The number of attributes placed in the center of the diagram was positively correlated with age in all three contexts, with $r \mathrm{~s}=.24, .28$ and $.21, p \mathrm{~s}<.05$, for the context of family, school or work, and community/society respectively.

Moral Identity Motivation. To develop a coding scheme, a subset of 60 interviews $(\approx$ $25 \%$ of total sample) was randomly chosen. Coding categories were established inductively to best represent the range of interview responses without imposing any specific theoretical perspective on the data. Eight coding categories were deemed reflective of individual's motivation to maintain their moral identity in the three social contexts of family, work or school and community/society. These coding categories were labeled as follows: (1) self-interest, (2) consequences-relationships, (3) consequences-others, (4) reputation, (5) role model, (6) self ideals, (7) relationship ideals, and (8) unclassified (for a detailed description of these coding categories and interview examples see Table 2).

A second subset of 60 interviews was randomly select to determine agreement between two independent coders (first and second author) separately for the three interview contexts. For the context of family, intercoder agreement was $\kappa=.80$, for the context of work or school it was $\kappa=.85$ and for community/society $\kappa=.75$. Discrepancies between coders were discussed and resolved unanimously. Relative frequencies for the eight coding categories combined across all 
three contexts ranged from $2.8 \%$ to $32.2 \%$ (see Table 2). Note that multiple responses were possible per context. Seven interviews were unscorable due to equipment failure or inaudibility of speech in critical interview sections.

As described above, coding categories were defined to capture the full range of response types and did not a priori represent external versus internal moral identity motivation. Following scale analyses conducted by Ryan and Connell (1989) and Weinstein and Ryan (2010), as well as general descriptions of the various levels of self-integration as defined by SDT, the two categories self-interest and reputation were combined to represent external moral identity motivation. Both coding categories reflect a focus on consequences of moral actions that are external to the self. By contrast, the coding categories consequences-others, role model, self ideals, and relationship ideals express identification with moral values. They were therefore combined to one single category group representing internal moral identity motivation. A concern for consequences of moral actions for relationships can be indicative of an external or an internal motivation and does not differentiate between the two types of motivations. It was therefore kept as a separate category group. Thus, three category groups were used in the main analyses reflecting external, internal or relationship-oriented moral identity motivation. Scores for each category group were calculated by tallying coding categories that belonged to one group. This was done separately for the three contexts of family, work or school, and community/society. Since multiple responses were possible in each context and since the internal and external category groups contained multiple coding categories, this sum score was openended and had no theoretically defined maximum.

Table 3 displays mean values, standard deviations and ranges for the category groups. Scores reflect the number of times a particular type of motivation (external, internal or 
relationship-oriented) was invoked in a given context by research participants. For external and internal motivation most scores ranged from 0 to 2 . The numerical value of 0 indicates that in a given context a participant's response did not fit any coding category that make up the category groups of moral identity motivation. By contrast, the numerical value of 2 indicates that a participant's responses fit two coding categories from the same category group in a given context (e.g., self ideal and role model for internal motivation in the context of family). Note, that unlike percentage scores these numerical values are analytically independent. Thus, scores for one category group do not affect scores for any other category group.

Despite analytical independence, external, internal and relationship-oriented categories were empirically correlated (see Table 4). Consistent with SDT, correlations between external and internal motivation were substantially negative in all three contexts, while consistencies across the three contexts were moderate, with a median correlation of $r=.27$.

Self-Importance of Moral Values. In addition to moral identity motivation, selfimportance of moral values was assessed by averaging self-importance ratings of the selected 1215 value-attributes across social contexts $(1=$ not important to me to $4=$ very important to me $)$. Internal consistency for this scale was $\alpha=.84$. Sample mean was $3.29, S D=0.31$.

\section{Results}

\section{Identification of Control Variables}

Krettenauer et al. (2016) reported a positive correlation between self-importance of moral values and age. Correspondingly, in the present paper, the number of value-attributes that were considered very important to the self was positively correlated with age (see Method section). Both variables may account for age-related differences in moral identity motivation. In addition, 
even though gender, ethnicity and SES were not significantly related to age in the present sample, the sample was not fully balanced with regard to these characteristics.

In order to identify potential confounds of effects of age, we examined bivariate correlations between moral identity motivation on the one hand, and self-importance of moral values, number of very important value-attributes as well as demographic characteristics on the other. Findings are summarized in Table 5. The self-importance of moral values as well as the number of value-attributes that were considered very important to the self was correlated with some aspects of individuals' moral identity motivation, even though effect sizes were small. Both variables were therefore used as statistical controls in the main analyses. Gender, ethnicity and SES, by contrast, were unrelated to moral identity motivation.

\section{Main Analyses}

In order to investigate age-related differences in moral identity motivation across social contexts, a mixed model ANOVA with repeated measures of moral identity motivation (external, relationship-oriented, internal) in three different contexts (family, work or school, community/society), as well as age-group (adolescence, emerging adulthood, young adulthood, middle age) as between-subject factor and self-importance of moral values as well as number of value attributes placed at the center of the diagram as covariates was run. This procedure did not yield any significant main effects for within- and between-subject factors and the covariates.

Only one two-way interaction reached the level of statistical significance: moral identity motivation by age group, $F(6,462)=2.36, p=.031$, partial $\eta^{2}=.029$, indicating that moral identity motivation differed across age groups. The three-way interaction was not significant, $F$ $(12,690)=0.56, p=.36$, partial $\eta^{2}=.019$. Differences between age groups for moral identity 
motivation (averaged across contexts) were followed up by univariate ANOVAs and post-hoc tests (Scheffe, $p<.05)$.

For external moral identity motivation, significant differences between age-groups were found, $F(3,233)=4.02, p<.01$, partial $\eta^{2}=.065$. Adolescence scored highest in external moral identity motivation and significantly differed from young adults who scored lowest (see Table 6). For relationship concerns, no differences between age-groups were found, $F(3,233)=0.78, p=$ .51 , partial $\eta^{2}=.010$. For internal moral identity motivation, again, significant differences between age-groups emerged $F(3,233)=3.77, p=.01$, partial $\eta^{2}=.046$. Younger adolescents scored significantly lower than older adults in internal moral identity motivation.

\section{Follow-up Analysis}

As indicated in Table 6, differences in external and internal moral identity motivation tended to be larger between the two younger age-groups than the older two age-groups, suggesting a non-linear effect of age. However, since age-groups in the present study were not equidistant with regard to participants' age any group comparison may underestimate this effect.

To examine non-linear relationships between age and moral identity motivation, we run follow-up regression analyses with linear and square-root effects for age (in years) and external as well as internal identity motivation (each averaged across the three contexts of family, work or school, community) as dependent variables. Findings of these analyses are summarized in Table 7. The inclusion of square-root effects after controlling for the linear effect of age yielded a significant increment in explained variance for both external and internal moral identity motivation. Figure 1 displays the joint linear and square-root effects of age. In line with, the post-hoc comparisons of age groups, the decrease in external motivation and the increase in internal motivation was stronger for younger participants. 


\section{Discussion}

This study was meant to investigate age-related differences in moral identity motivation. Although moral identity is considered an important developmental construct, empirical support for systematic development in moral identity has been limited so far (Krettenauer \& Hertz, 2015; Hardy et al. 2014).

It was found that external moral identity motivation decreases with age whereas internal motivation increases. These effects were not merely due to self-importance of moral values. While self-importance of moral values was positively correlated with internal motivation and inversely associated with external motivation, age-related differences in moral identity motivation were present even when controlling for these effects. Effects of age were larger in adolescence and emerging adulthood than in adulthood. It is important to note, however, that external and internal moral identity motivation was evident in all age groups and that age-related differences were gradual rather than abrupt. Overall, findings are consistent with SDT, which posits a developmental trend toward higher levels of self-integration. However, in the context of the present study it remains an open question to be addressed in future studies whether this trend is driven by decreases in external motivation, increases in internal motivation, or both. In the present study, both types of motivation were treated as independent constructs even though they were negatively correlated (see Table 4).

Contrary to our expectation, we did not find significant differences in moral identity motivation across the contexts of family, work or school, and community/society. Even though there was a tendency for moral identity motivation to be more external and less internal in the context work or school (see Table 3), this tendency did not reach the level of statistical significance once self-importance of moral values was statistically controlled. Note, however, 
when running the same mixed-model ANOVA as reported in the main analysis section without controlling for self-importance of moral values the interaction between moral motivation and context turned out to be significant, $F(4,230)=28.54, p<.01$, partial $\eta^{2}=.332$. This finding suggests that context differences in moral identity motivation are present but are not unique in that they are attributable to the self-importance of moral values. Lower self-importance of moral values was associated with lower internal and higher external moral identity motivation particularly in the context of work or school (see Table 5). As a consequence, unique effects of context did not emerge.

A major limitation of the study is in its cross-sectional design, which made it impossible to track individual change over time. Moreover, any age-related differences may be confounded with cohort effects. Empirical evidence for developmental effects in moral identity obtained in the present study is therefore only indirect. Secondly, the sample of the present study was culturally rather heterogeneous which prevented culture-specific analyses and, as a consequence, may obscure effects of culture. Moreover, age-groups were not equidistant with regard to age and adult age groups were small in relation to the large age spans they represented. Finally, the assessment of moral identity was based on individuals' idiosyncratic conceptions of a highly moral person, which was found to be modestly related with age in previous studies (Krettenauer et al., 2016). This assessment strategy may have boosted age-related differences in moral identity motivation since the values individuals include in their moral identity sometimes go beyond the moral domain as defined by domain theory (Smetana et al., 2014) to include personal and conventional issues. Thus, it would important to replicate findings by applying a more restrictive definition of the moral domain that does not vary across individuals. 
Future research will have to address these limitations. At the same time, it will be important to systematically investigate factors that influence growth of internal moral identity motivation particularly in adolescence and emerging adulthood. Internal (autonomous) motivation has been shown to be a stronger predictor of actual behavior than external motivation in a broad range of areas (e.g., academic achievement, health behavior, prosocial behavior, cf. Deci \& Ryan, 2012). Even though, internal moral identity motivation as investigated in the present study does not reflect motifs for moral action (see introduction), it may strengthen a person's overall motivation to uphold moral intentions in the face of conflicting desires and interests. If this assumption is valid, growth of internal moral identity motivation should be considered an important goal of moral development. 


\section{References}

Arnold, M. L. (1993). The place of morality in the adolescent self. Unpublished doctoral dissertation, Harvard University, Cambridge.

Assor, A. (2012). Autonomous moral motivation: Consequences, socializing antecedents, and the unique role of integrated moral principles. In M. Mikulincer \& P. R. Shaver (Eds.), The Social Psychology of morality: Exploring the causes of good and evil (pp. 239-255). Washington, DC: American Psychological Association.

Barriga, A. Q., Morrison, E. M., Liau, A. K., \& Gibbs, J. C. (2001). Moral Cognition: Explaining the Gender Difference in Antisocial Behavior. Merrill-Palmer Quarterly. http://doi.org/10.1353/mpq.2001.0020

Deci, E. L., \& Ryan, R. M. (2012). Motivation, personality, and development within embedded social contexts: An overview of self-determination theory. In R. M. Ryan (Ed.), The Oxford Handbook of Human Motivation (pp. 85-107). Oxford: Oxford University Press.

Frankena, W. K. (1963). Ethics. Eglewood Cliffs, NJ: Prentice-Hall.

Ganzeboom, H. B. G., De Graaf, P. M., \& Treiman, D. J. (1992). A standard international socioeconomic index of occupational status. Social Science Research, 21(1), 1-56. http://doi.org/10.1016/0049-089X(92)90017-B

Hardy, S., \& Carlo, G. (2011). Moral Identity: What is it, how does it develop, and is it linked to moral action? Child Development Perspectives, 5, 212-218.

Johnston, M., \& Krettenauer, T. (2011). Moral self and moral emotion expectancies as predictors of anti- and prosocial behaviour in adolescence: A case for mediation? European Journal of Developmental Psychology, 8(2), 228-243. http://doi.org/10.1080/17405621003619945 
Krettenauer, T. (2011). The dual moral self: moral centrality and internal moral motivation. The Journal of Genetic Psychology, 172(4), 309-28. http://doi.org/10.1080/00221325.2010.538451

Krettenauer, T., \& Hertz, S. (2015). What develops in moral identities? A critical review. Human Development, 58(3), 137-153. http://doi.org/10.1159/000433502

Krettenauer, T., Murua, L. A., \& Jia, F. (2016). Age-related differences in moral identity across adulthood. Developmental Psychology, 52(6), 972-984. http://doi.org/http://dx.doi.org/10.1037/dev0000127

Nucci, L. (2004). The promise and limitations of the moral self construct. In C. Lightfoot, C. E. Lalonde, \& M. J. Chandler (Eds.), Changing conceptions of psychological life (pp. 49-70). Mahwah, NJ: Erlbaum.

Nunner-Winkler, G., Meyer-Nikele, M., \& Wohlrab, D. (2007). Gender Differences in Moral Motivation. Merrill-Palmer Quarterly (Vol. 53).

Renaud-Dubé, A., Taylor, G., Lekes, N., Koestner, R., \& Guay, F. (2010). Adolescents' motivation toward the environment: Age-related trends and correlates. Canadian Journal of Behavioural Science/Revue Canadienne Des Sciences Du Comportement, 42(3), 194 199. http://doi.org/10.1037/a0018596

Ryan, R. M., \& Connell, J. P. (1989). Perceived locus of causality and internalization: Examining reasons for acting in two domains. Journal of Personality and Social Psychology, 57, 749-761.

Sheldon, K. M., \& Kasser, T. (2001). Getting older, getting better? Personal strivings and psychological maturity across the life span. Developmental Psychology, 37, 491-501. 
Sheldon, K. M., Kasser, T., Houser-Marko, L., Jones, T., \& Turban, D. (2005). Doing one’s duty: Chronological age, felt autonomy, and subjective well-being. European Journal of Personality, 19(2), 97-115. http://doi.org/10.1002/per.535

Smetana, J. G., Jambon, M., \& Ball, C. (2014). The social domain approach to children's moral and social judgments. In M. Killen \& J. G. Smetana (Eds.), Handbook of moral development (pp. 23-45). New York: Psychology Press.

Vauclair, C.-M., Wilson, M., \& Fischer, R. (2014). Cultural conceptions of morality: Examining laypeople's associations of moral character. Journal of Moral Education, 43(1), 54-74. http://doi.org/10.1080/03057240.2013.873365

Weinstein, N., \& Ryan, R. M. (2010). When helping helps: Autonomous motivation for prosocial behavior and its influence in well-being for the helper and the recipient, Journal of $(98)$, 222-244. http://doi.org/10.1037/a0016984 


\section{Appendix}

Value-attributes as used in the moral identity interview

For details about the process of attribute selection see Krettenauer, Murua, and Jia (2016).

$\begin{array}{cccc}\text { accepting } & \text { faithful } & \text { just } & \text { reliable } \\ \text { altruistic } & \text { follows the rules } & \text { kind } & \text { religious } \\ \text { benevolent } & \text { forgiving } & \text { knowledgeable } & \text { respectful } \\ \text { caring } & \text { friendly } & \text { knows what } & \text { responsible } \\ \text { cheerful } & \text { fun } & \text { law-abiding } & \text { righteous } \\ \text { clean } & \text { generous } & \text { listens } & \text { self-assured } \\ \text { compassionate } & \text { genuine } & \text { loving } & \text { self-disciplined } \\ \text { confident } & \text { good } & \text { loyal } & \text { selfless } \\ \text { conscientious } & \text { grateful } & \text { makes the } & \text { sharing } \\ \text { considerate } & \text { happy } & \text { right choices } & \text { sincere } \\ \text { consistent } & \text { hard-working } & \text { modest } & \text { sociable } \\ \text { cooperative } & \text { has high standards } & \text { non-judgmental } & \text { strong } \\ \text { courageous } & \text { has integrity } & \text { obedient } & \text { thrifty } \\ \text { courteous } & \text { healthy } & \text { open-minded } & \text { tolerant } \\ \text { dependable } & \text { helpful } & \text { optimistic } & \text { trustworthy } \\ \text { educated } & \text { honest } & \text { patient } & \text { truthful } \\ \text { empathic } & \text { honorable } & \text { perseveres } & \text { understanding } \\ \text { ethical } & \text { humble } & \text { proper } & \text { upstanding } \\ \text { exemplary } & \text { independent } & \text { rational } & \text { virtuous } \\ \text { fair } & \text { intelligent } & \text { wise }\end{array}$


Table 1

Demographic Characteristics of Sample Across Age Groups

\begin{tabular}{|c|c|c|c|c|c|}
\hline & $\begin{array}{l}\text { Adolescent } \\
(14-18 \text { years })\end{array}$ & $\begin{array}{l}\text { Emerging Adulthood } \\
(19-25 \text { years })\end{array}$ & $\begin{array}{l}\text { Young Adulthood } \\
\text { (26-45 years) }\end{array}$ & $\begin{array}{l}\text { Middle Age } \\
\text { (46-65 years) }\end{array}$ & Total \\
\hline $\mathrm{N}$ & 67 & 52 & 66 & 67 & 252 \\
\hline Male $(\%)^{\mathrm{a}}$ & $26(38.8)$ & $23(44.2)$ & $23(34.9)$ & $32(47.8)$ & $104(41.3)$ \\
\hline Age in years $(\mathrm{SD})$ & $16.41(1.62)$ & $22.09(2.37)$ & $32.81(5.57)$ & $58.70(7.07)$ & $33.48(16.98)$ \\
\hline European-Canadian $(\%)^{\mathrm{a}}$ & $51(75.6)$ & $34(65.0)$ & $53(78.9)$ & $56(83.5)$ & $193(76.1)$ \\
\hline Educational attainment ${ }^{\mathrm{b}}$ & N/A & $10.0 / 50.0 / 40.0$ & $8.9 / 58.9 / 32.1$ & $10.6 / 50.0 / 39.4$ & $9.8 / 53.8 / 36.4$ \\
\hline $\begin{array}{l}\text { Socio-Economic Status } \\
\text { (ISEI) }\end{array}$ & $50.21(12.50)$ & $50.81(15.81)$ & $49.20(15.79)$ & $51.75(15.21)$ & $50.46(14.69)$ \\
\hline
\end{tabular}

Note. ${ }^{\text {a }}$ column $\%$

b $\%$ of participants with high-school diploma / undergraduate or college degree / graduate or professional degree 
Table 2

Coding Categories and Category Groups for Moral Identity Motivation

\begin{tabular}{|c|c|c|c|c|}
\hline $\begin{array}{l}\text { Coding } \\
\text { Category }\end{array}$ & $\begin{array}{l}\text { Category } \\
\text { Group }^{\mathrm{a}}\end{array}$ & Definition & Interviewexample & $\%^{b}$ \\
\hline Self-Interest & $\mathrm{E}$ & $\begin{array}{l}\text { Being moral is } \\
\text { instrumental for staying } \\
\text { out of trouble and for } \\
\text { gaining rewards }\end{array}$ & $\begin{array}{l}\text { And I think it's important to be honest because there's many things } \\
\text { that can go wrong in your life but your family is the main thing that } \\
\text { can help you to get back to being, being good and successful and } \\
\text { happy and stuff so then you have to be honest. }\end{array}$ & 32.2 \\
\hline $\begin{array}{l}\text { Consequences- } \\
\text { others }\end{array}$ & I & $\begin{array}{l}\text { Being moral is important } \\
\text { for others' well-being }\end{array}$ & I think it's important so that other people aren't hurt. & 4.8 \\
\hline
\end{tabular}


Role model I Being moral is important to set a good example for others and to teach others about the importance of moral values

Self ideals I Being moral reflects the type of person one aspires to be

$\begin{array}{lll}\begin{array}{l}\text { Relationship } \\ \text { ideals }\end{array} & \text { I } & \begin{array}{l}\text { Being moral reflects the } \\ \text { type of } \\ \text { relationships/community } \\ \text { the person wants to be part } \\ \text { of. }\end{array} \\ \text { Others } & - & \begin{array}{l}\text { Responses do not fit in any } \\ \text { coding category either } \\ \text { because they are } \\ \text { unelaborated or too } \\ \text { ambiguous. }\end{array} \\ & \end{array}$

So if you want others to do the same thing then I guess it's something that you need to display yourself, live by the same things that you want others to live by.

Because I feel that's what makes a moral person and I want to be a moral person.

I think that the heart of the community is, it's a community that cares for one another. It's also open-minded to all possibilities. Particularly if you're trying to have a community that is inclusive, you have to be open to all possibilities and not to marginalize minorities and so forth.

Notes. ${ }^{\mathrm{a}} \mathrm{E}=$ External $\mathrm{I}=$ Internal, $\mathrm{R}=$ Relationship-oriented, ${ }^{\mathrm{b}}$ Percentage based on total number of coded responses $(N=864)$ 
Table 3

Means, Standard Deviations and Ranges (in Parentheses) for Moral Identity Motivation Across

Contexts

\section{Context}

\begin{tabular}{lccc}
\cline { 2 - 4 } Motivation & \multicolumn{1}{c}{ Family } & Work or School & Community/Society \\
\hline External & $0.31(0.46,0-1)$ & $0.68(0.49,0-2)$ & $0.40(0.53,0-2)$ \\
Relationship-oriented & $0.39(0.48,0-1)$ & $0.15(0.34,0-1)$ & $0.37(0.48,0-1)$ \\
Internal & $0.36(0.52,0-2)$ & $0.24(0.43,0-2)$ & $0.36(0.50,0-2)$ \\
\hline
\end{tabular}


Table 4

Bivariate Correlations Between Measures of Moral Identity Motivation Across Contexts

Family Work or School Community/Society

Family

Work or School

Community/Society
$-.24^{\mathrm{E}-\mathrm{R}} /-.38^{\mathrm{R}-\mathrm{I}} /-.43^{\mathrm{E}-\mathrm{I}}$

$.21^{\mathrm{E}} / .21^{\mathrm{R}} / .45^{\mathrm{I}}$

$-.41^{\mathrm{E}-\mathrm{R}} /-.18^{\mathrm{R}-\mathrm{I}} /-$

$.62^{\mathrm{E}-\mathrm{I}}$

$.25^{\mathrm{E}} / .31^{\mathrm{R}} / .32^{\mathrm{I}}$

$.28^{\mathrm{E}} / .23^{\mathrm{R}} / .33^{\mathrm{I}}$

$-.37^{\mathrm{E}-\mathrm{R}} /-.35^{\mathrm{R}-\mathrm{I}} /-.49^{\mathrm{E}-}$

I

Notes. $N=237$, all coefficients $(r)$ are statistically significant, $p<.01$

Category groups of moral identity motivation: ${ }^{\mathrm{E}}$ external, ${ }^{\mathrm{R}}$ relationship-oriented, ${ }^{\mathrm{I}}$ internal Coefficients in main diagonal represent correlations of category groups within contexts Coefficients below main diagonal represent correlations of category groups across contexts 
Table 5

Bivariate Correlations between Moral Identity Motivation and Self-Importance of Moral Values, Number of Very-Important Value Attributes and Demographic Characteristics

\begin{tabular}{|c|c|c|c|c|c|c|c|c|c|}
\hline & \multicolumn{3}{|c|}{ External } & \multicolumn{3}{|c|}{$\begin{array}{c}\text { Relationship- } \\
\text { oriented }\end{array}$} & \multicolumn{3}{|c|}{ Internal } \\
\hline & $\mathbf{F}$ & WS & $\mathbf{C}$ & $\mathbf{F}$ & WS & $\mathbf{C}$ & $\mathbf{F}$ & WS & $\mathbf{C}$ \\
\hline Self-importance of moral values & -.08 & $-.19 * *$ & -.07 & -.04 & .07 & .08 & $.13^{*}$ & $.19 * *$ & .08 \\
\hline Number of very important value-attributes & -.05 & $-.14 *$ & -.05 & -.04 & .01 & .03 & $.13^{*}$ & $.14^{*}$ & .09 \\
\hline Gender $(1=$ male, $0=$ female $)$ & .05 & .06 & .01 & -.01 & .06 & .05 & -.03 & -.11 & -.07 \\
\hline Ethnicity (European-Canadian, $1=$ yes, $0=n o$ ) & -.05 & -.01 & .01 & -.04 & .01 & -.01 & .03 & -.08 & -.05 \\
\hline Socio-Economic Status (ISEI) & -.09 & -.00 & .00 & -.00 & .01 & -.02 & .08 & .03 & .09 \\
\hline
\end{tabular}

Note $\mathrm{F}=$ Family, $\mathrm{WS}=$ Work or School, $\mathrm{C}=$ Community $/$ Society

$N=242, * p<.05, * * p<.01$ 
Table 6

Means and Standard Errors for Moral Identity Motivation by Age-Groups

\begin{tabular}{lcccc} 
& \multicolumn{4}{c}{ Age-Group } \\
\cline { 2 - 5 } Motivation & $\begin{array}{c}\text { Adolescence } \\
(14-18 \text { years })\end{array}$ & $\begin{array}{c}\text { Emerging Adulthood } \\
(19-25 \text { years })\end{array}$ & $\begin{array}{c}\text { Young Adulthood } \\
(26-45 \text { years })\end{array}$ & $\begin{array}{c}\text { Middle Age } \\
(46-65 \text { years })\end{array}$ \\
\hline External & $0.55^{\mathrm{a}}(0.040)$ & $0.46^{\mathrm{a}, \mathrm{b}}(0.045)$ & $0.33^{\mathrm{b}}(0.041)$ & $0.38^{\mathrm{a}, \mathrm{b}}(0.041)$ \\
Relationship-oriented & $0.25^{\mathrm{a}}(0.036)$ & $0.31^{\mathrm{a}}(0.041)$ & $0.31^{\mathrm{a}}(0.037)$ & $0.26^{\mathrm{a}}(0.037)$ \\
Internal & $0.19^{\mathrm{a}}(0.043)$ & $0.30^{\mathrm{a}, \mathrm{b}}(0.048)$ & $0.36^{\mathrm{a}, \mathrm{b}}(0.044)$ & $0.38^{\mathrm{b}}(0.044)$ \\
\hline
\end{tabular}

Note. Means in the same row with different superscripts indicate significant group differences (post hoc Scheffe, $p<.05$ ) 
Table 7

Regression of External and Internal Moral Identity Motivation on Age

\begin{tabular}{|c|c|c|c|c|c|c|c|c|}
\hline \multirow[b]{3}{*}{ Predictors } & \multicolumn{4}{|c|}{ External Motivation } & \multicolumn{4}{|c|}{ Internal Motivation } \\
\hline & \multicolumn{2}{|c|}{ Step 1} & \multicolumn{2}{|c|}{ Step 2} & \multicolumn{2}{|c|}{ Step 1} & \multicolumn{2}{|c|}{ Step 2} \\
\hline & $b$ & $t$ & $b$ & $t$ & $b$ & $t$ & $b$ & $t$ \\
\hline Age in years (linear) & -0.01 & $-2.37 *$ & 0.14 & $3.49 * *$ & 0.10 & $2.46^{*}$ & -0.09 & $-2.17 *$ \\
\hline Age in years (square root) & & & -1.79 & $-3.71 * *$ & & & 1.25 & $2.41 *$ \\
\hline$\Delta R^{2}$ & & $3 *$ & & $4 * *$ & & & & $24 *$ \\
\hline
\end{tabular}

Note. $N=237$

$* * p<.01, * p<.05$. 


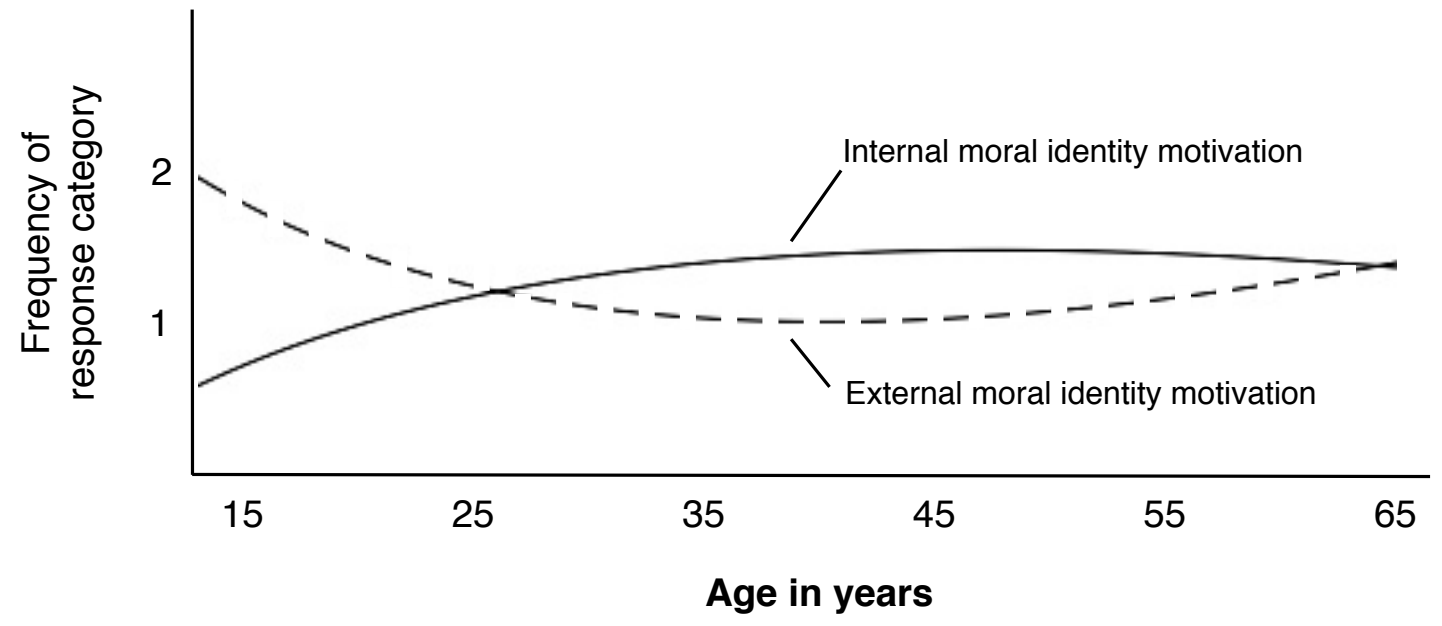

Figure 1.

Joint linear and square-root effects of age on internal and external moral identity motivation 